Civil Engineering

Volume 167 Issue CE1

'Building with nature': the new Dutch approach to coastal and river works

de Vriend, van Koningsveld and Aarninkhof

\section{ice | proceedings}

Proceedings of the Institution of Civil Engineers
Civil Engineering 167 February 2014 Issue CE1

Pages 18-24 http://dx.doi.org/10.1680/cien.13.00003

Paper 1300003

Received 02/02/2013 Accepted 19/04/2013

Keywords: environment / sea defences / sustainability

$\square$

ie

Institution of Civil Engineers

ICE Publishing: All rights reserved

\title{
"Building with nature": the new Dutch approach to coastal and river works
}

1 Huib de Vriend PhD

Professor of eco-hydraulics, Delft University of Technology, the Netherlands and scientific director of the 'building with nature' innovation programme
2 Mark van Koningsveld PhD

Manager environmental engineering, Van Oord Dredging and Marine Contractors, the Netherlands

3 Stefan Aarninkhof PhD

Senior engineer, Hydronamic, Royal Boskalis Westminster, the Netherlands
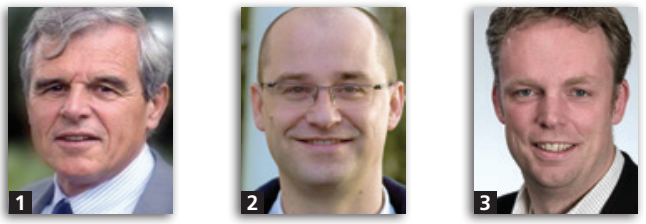

The Netherlands has adopted a new, proactive approach to developing its extensive coastal and river works called 'building with nature'. Rather than simply minimising or mitigating the environmental impact of harbours, navigation channels, land reclamation and flood defences, the idea is to make use of the dynamics of the natural environment and provide opportunities for natural processes. Existing concepts and ideas have been further developed and tested in a number of full-scale pilot experiments, including sand engines, oyster reefs and waveattenuating forests. This paper describes a number of these experiments along with the preliminary results and lessons learned.

\section{Introduction}

An increasing proportion of the world's population lives in lowlying areas near rivers, deltas and the sea, particularly in new coastal megacities (World Bank, 2010).

As the world's population grows and prosperity levels rise, so too will the demand for goods and services. Accommodating this growth will thus require the development of further hydraulic infrastructure such as harbours, access channels, land-reclamation schemes and flood defences. Sea level rise and climate change also mean these designs need to be adaptable.

At the same time, more people need more space for recreation - such as beaches, parks and waterfronts - which generates its own special demands on spatial and infrastructure planning. All of these developments need to be realised in a sustainable manner in often fragile littoral environments that are under constant pressure. Balancing the sustainable functioning of ecosystems with the demand for economic development is one of the greatest challenges for the future of humankind.

It is thus crucial that civil engineers learn to design infrastructure that can serve more than just one purpose, that works in line with natural processes rather than against them and that is adaptable to changing conditions such as sea level rise and climate change. Traditional approaches focus on minimising the negative impacts of envisaged infrastructural projects and compensating for any residual negative effects. As a next step beyond these reactive approaches, 'building with nature' aims to be proactive, utilising natural processes and providing opportunities for nature as part of the infrastructure development process.

This paper presents the further development of existing building with nature ideas and concepts (e.g. McHarg, 1969; Waterman, 2008).

\section{Coastal defence}

Around the world many eroding sandy coasts are being maintained by nourishment - that is, adding sand to beach or foreshore. Much of the $350 \mathrm{~km}$ long North Sea coast of the Netherlands tends to erode as a result of the combined effects of diminishing supplies of river sediments, ongoing land subsidence and rising sea level. Finding effective ways to counter this structural erosion is an urgent priority as it seriously threatens the flood protection and other functions of the coastal system (Stive et al., 2011).

Since 1990 the preferred method of intervention is to nourish the coast at regular intervals with small volumes of sand dredged from the North Sea. The total volume of sand needed for these nourishments has steadily increased, from 6 million $\mathrm{m}^{3}$ in 1990 to over 12 million $\mathrm{m}^{3}$ per year since 2001 .

Although nourishment as a means of coastal maintenance has many advantages, the present practice for the Dutch coast leads to rather a frequent repetition, typically every $4-5$ years. Every time, the coastal 


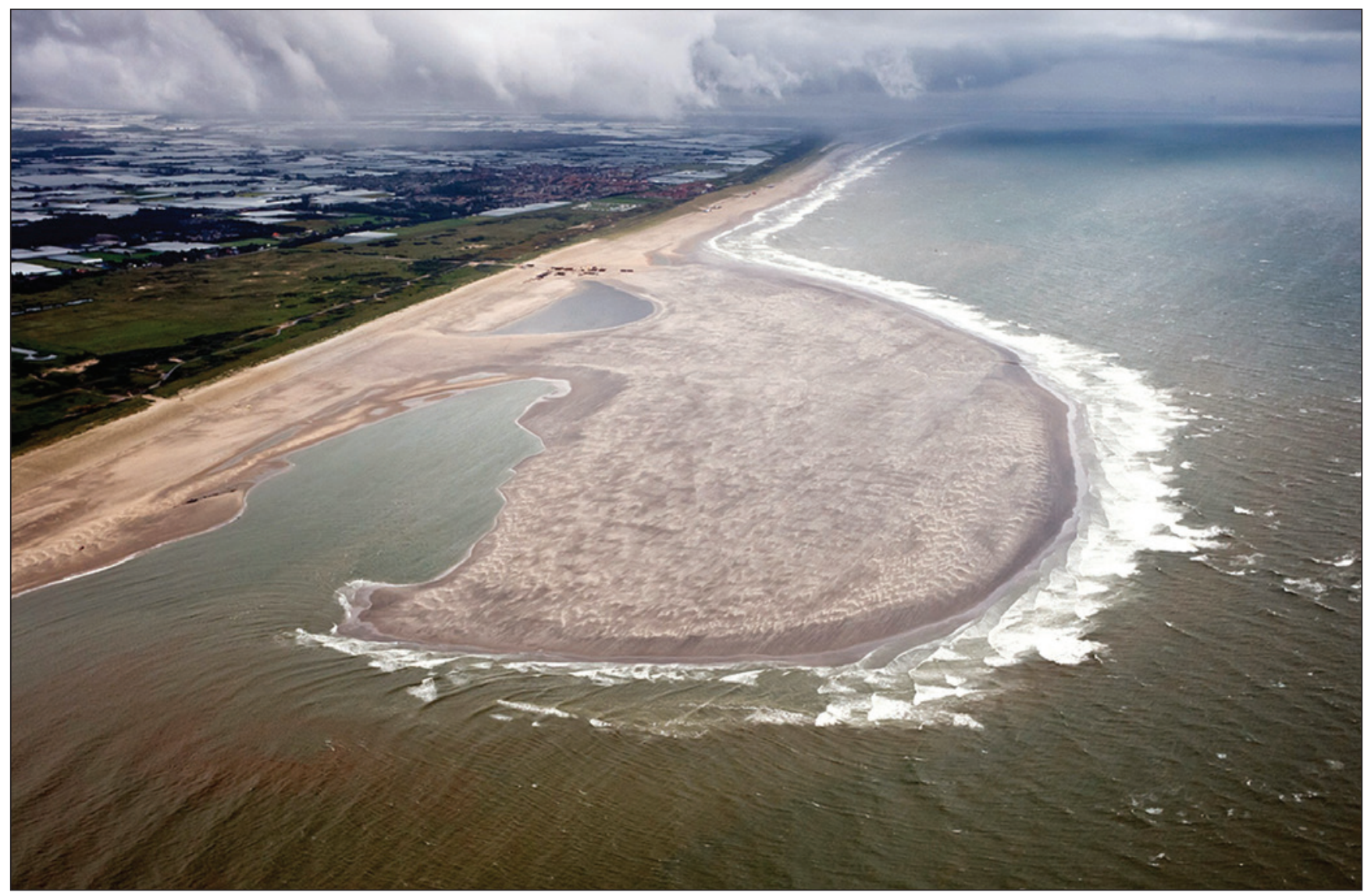

Figure 1. Delfland sand engine in July 2011, just after completion - a total of 20 million $\mathrm{m}^{3}$ of sand was placed in front of the existing shore (https://beeldbank.rws.nl, Rijkswaterstaat / Joop van Houdt)

ecosystem is disturbed and needs several years to recover, such that it is in a more or less permanent state of disturbance (Baptist et al., 2008). Moreover, consistently feeding the beach or the upper shore leads to over-steepening of the coastal profile and hence to an increasing need to nourish (Stive et al., 1991). These were reasons to develop the concept of concentrated nourishments.

The idea is to deposit a significant stock of sand in one location, which is then gradually redistributed across and along the shore by wind, waves and currents. By making use of these natural processes to redistribute the sand, this innovative approach aims to limit the disturbance of local ecosystems, while also providing new areas for nature and recreation. Moreover, as nature does part of the work, the price per unit sand will generally be lower.

The Delfland 'sand engine' is a full-scale experiment with a concentrated nourishment on the Dutch coast, initiated by the province of South Holland and the Ministry of Infrastructure and the Environment. In 2011, 20 million $\mathrm{m}^{3}$ of sand was placed on the shore (Figure 1), expected to be enough for some 20 years. The shape of the nourishment was inspired by the potential of the coast to provide areas for nature and recreation. The hook-shaped peninsula would provide resting areas for seals at the end of the spit, with a shallow lagoon that would offer habitats for flatfish. Part of the sand would be transported onshore and contribute to the dune front while promoting the development of pioneer dunes and associated vegetation.

The first monitoring results (Figure 2) show that so far the sand engine is behaving as predicted. Sediment is indeed being transported along and towards the coast, seals are visiting the area, young dunes are forming, pioneer plant species are beginning to settle and the lagoon is a nursery for flatfish. Also, the sand engine turns out to be a hotspot for wind, wave and kite surfers.

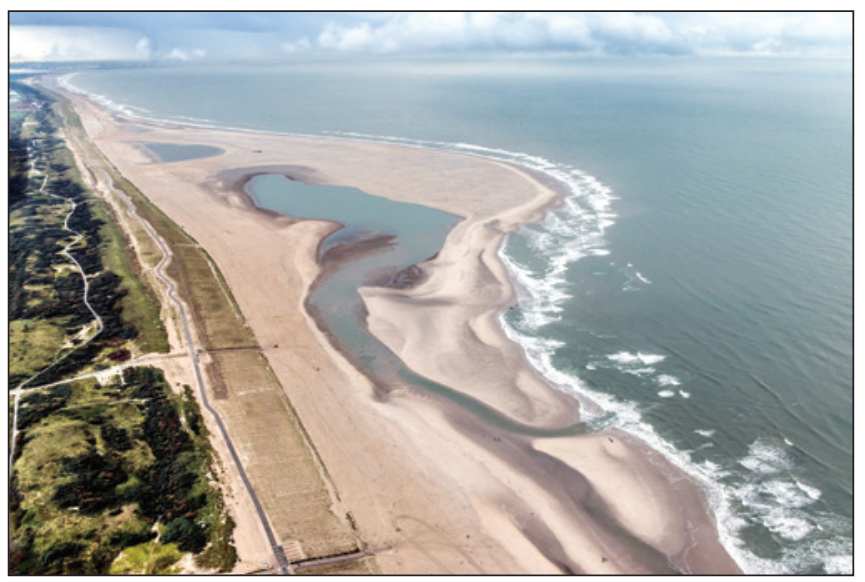

Figure 2. Delfland sand engine in October 2012 - sediment is being transported along the coast, young dunes are forming, pioneer plant species are beginning to settle and the lagoon is a nursery for flatfish (https://beeldbank.rws.nl, Rijkswaterstaat / Joop van Houdt) 


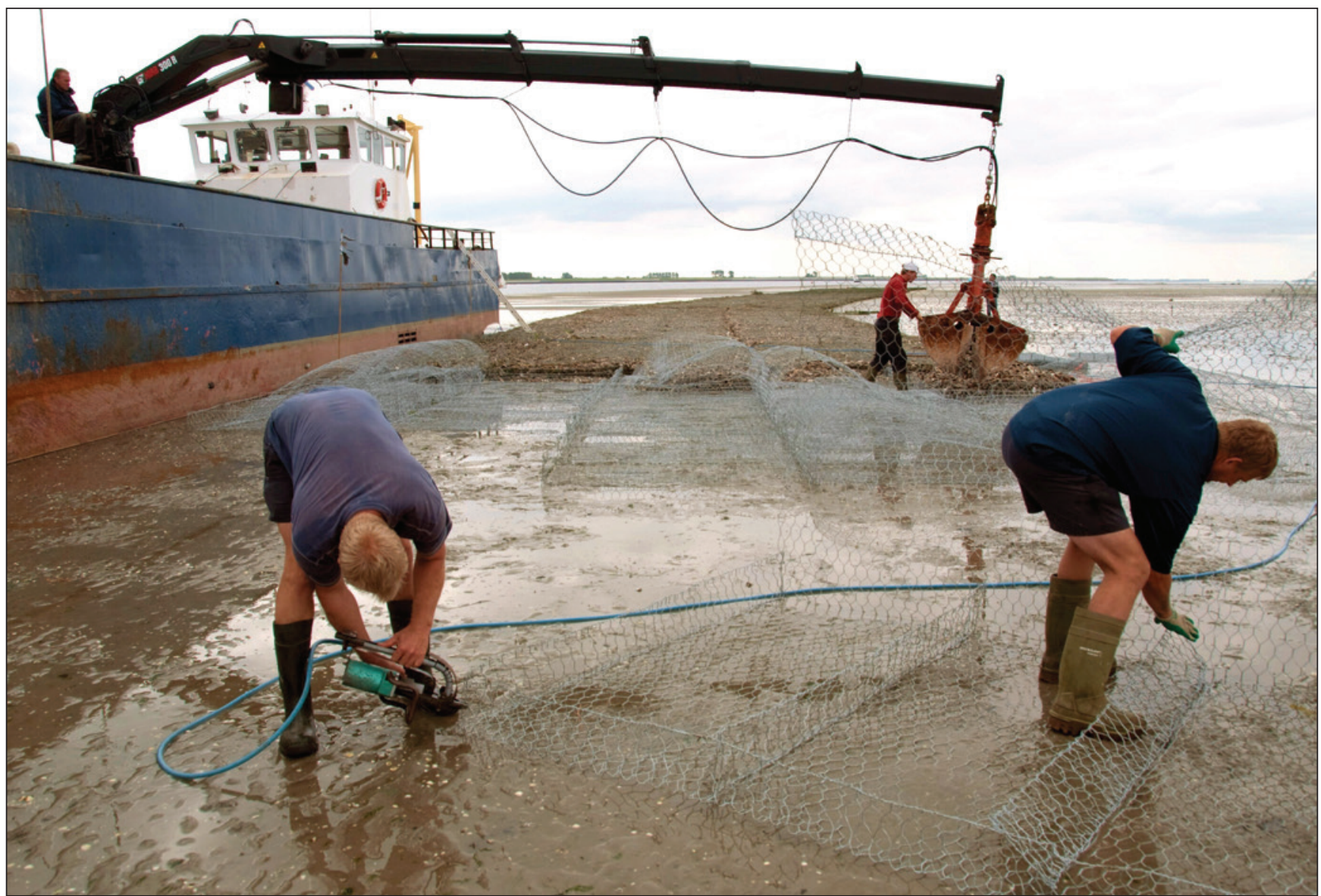

Figure 3. Oosterschelde oyster reef under construction - old oyster shells in steel wire gabions are placed as a substrate (courtesy Tom Ysebaert)

\section{Estuarine environments}

Estuaries are among the world's most productive ecosystems as well as being attractive areas for economic development, including harbours, shipping, industry, fisheries and aquaculture. This explains why many estuaries have been heavily modified by engineering works. Most of these have been built for their primary function, at most attempting to limit the environmental impact. Long-term environmental effects, however, were seldom taken into consideration.

The movable storm surge barrier in the mouth of the Oosterschelde estuary, in the south-west of the Netherlands, is such an object. This prefabricated structure, an icon of civil engineering, was built primarily for flood protection, but most of the time it allows the tide to penetrate into the ecologically and economically valuable basin behind it. Due to good water quality, the Oosterschelde is an important area for the commercial production of shellfish such as mussels and oysters. However, the barrier has diminished both the tidal range and the average velocity of the tidal current in the basin by about a third.

As a result, the channels within the estuary are now deeper and wider than is needed to accommodate the reduced current and tend to fill in with sediment. This, and the altered hydrodynamics within the estuary, has led to the gradual erosion of the tidal flats. As the barrier and the adjacent scour holes effectively block sediment transport, large areas of these flats and the ecosystem services they provide are lost. Not only are tidal flats valuable, diverse and productive habitats, they also dissipate wave energy and so help to reduce wave attack on the dykes surrounding the basin.

Since there is little experience with protecting tidal flats from erosion, a number of pilot experiments in line with the building with nature concept are now being conducted in the estuary. One of them involves the use of shellfish reefs to keep sand from being transported into the tidal channels. In this case, the Pacific oyster (Crassostrea gigas), an imported species presently abundant in the Oosterschelde, is used as an 'ecosystem engineer'. This oyster builds three-dimensional reef structures that are effective in dissipating wave energy and protecting the sediment in its lee from erosion. When in good condition, these reefs are able to withstand the power of storm winds and waves.

To 'grow' a reef, a substrate of dead oyster shells is placed on the edge of the tidal flat (Figure 3). To prevent the shells being washed away with the tide or during storms, they are stowed in steel wire gabions. In the summer oyster larvae - which need a hard substrate on which to grow - attach themselves to the shells and gradually build up a solid reef structure. Once the oysters have established themselves, the steel wires corrode away, after which the reef will have to survive on its own, constantly renewing itself by attracting new larvae. 
Civil Engineering

Volume 167 Issue CE1 February 2014
'Building with nature': the new Dutch

approach to coastal and river works

de Vriend, van Koningsveld and Aarninkhof
The first monitoring results (Figure 4) show that the reefs are functioning as intended, although their success depends on the local environment. Oyster larvae are attaching themselves to the shells and are developing into adult oysters. The reefs are preventing erosion or even causing sedimentation in the areas in their lee. In one case there has been no erosion at all in the area protected by the reef, compared with about 2-3 cm erosion per year in unprotected parts of the estuary. However, at least one of the reefs in a very exposed area is trapping a lot of sand, which hampers the development of established oysters.

Based on the result, Dutch engineers and ecologists are now considering the application of shellfish reefs elsewhere in the world, for example in Bangladesh (see http://www.royalhaskoning.com/ en-GB/NewsAndDocumentation/Pages/bangladesh-shows-oysterreef-potential.aspx).

\section{Shallow lakes}

Shallow lakes are ubiquitous in low-lying sedimentation areas such as deltas. Some lakes (e.g. Peipsi in Estonia and Tai in China) are large enough to allow for significant storm-induced waves and water level set-up. The downwind shores of those lakes are generally susceptible to erosion until a shallow wave-attenuating platform has formed on the foreshore.

In the Netherlands, the closure of Zuiderzee by a $32 \mathrm{~km}$ long dam in 1932 has created a large shallow lake, the IJsselmeer. Although large parts have been reclaimed or separated, the size of the remaining lake is still significant at $1100 \mathrm{~km}^{2}$. It is filled by the IJssel, one of the Rhine branches, and a number of smaller rivers. Excess water is discharged by way of sluices in the closure dam. The Netherlands government is considering using the lake as a strategic freshwater reserve, which would imply a stronger variation of the water level than currently. Moreover, the land around the lake is subsiding due to geological effects, soft sediment compaction and peat oxidation.

At the north-east side of the lake, which is downwind of the strongest prevailing storms, there is a shallow foreshore platform. This probably explains the survival of the former salt marshes, which have

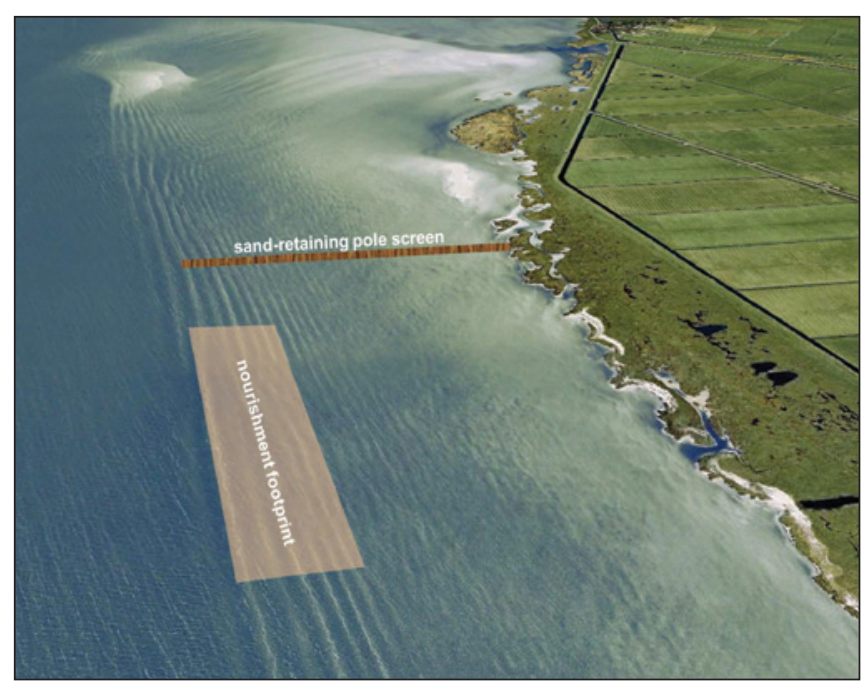

Figure 5. Workumerwaard shore nourishment design - $31500 \mathrm{~m}^{3}$ of dredged sediment was placed in a $600 \mathrm{~m}$ long, $100 \mathrm{~m}$ ridge around $600 \mathrm{~m}$ from the shore

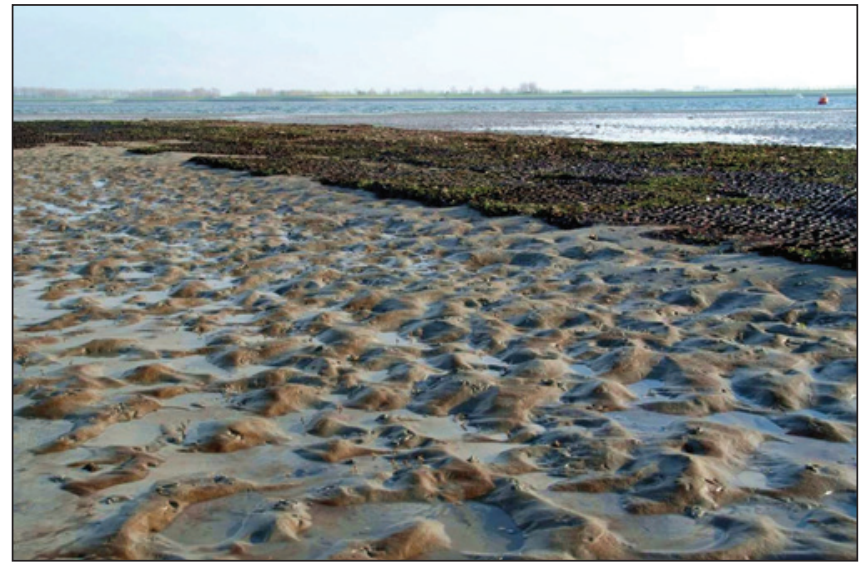

Figure 4. Oosterschelde oyster reef after 1 year - oyster larvae have attached themselves to the shell substrate and become full-sized, dissipating wave energy and protecting the mudflats from erosion (courtesy Tom Ysebaert)

turned into ecologically valuable (part of the Natura 2000 network) freshwater wetlands as the lake gradually desalinated. To enable these wetlands to withstand higher lake levels and stronger wave attack, and to cope with their gradual loss of diversity and vitality, they need to be revitalised. One way to achieve this might be slowly to nourish their shores with sediment, which would enable them to adapt to higher lake levels while creating room for pioneer species without destroying the existing vegetation. The latter should trap part of the sediment reaching the shore, thus raising the level of the wetland's seaward edge.

To test the idea, a full-scale experiment is being carried out on the shore of one of these wetlands, the Workumerwaard, a valuable nature reserve and bird sanctuary. In 2011, a $31500 \mathrm{~m}^{3}$ foreshore nourishment was placed in the form of a shore-parallel ridge some $600 \mathrm{~m}$ from the water line with a footprint of about $600 \mathrm{~m}$ by $100 \mathrm{~m}$ (Figure 5). The location was chosen such that waves and currents in this generally lowdynamic environment would gradually bring the sediment onshore.

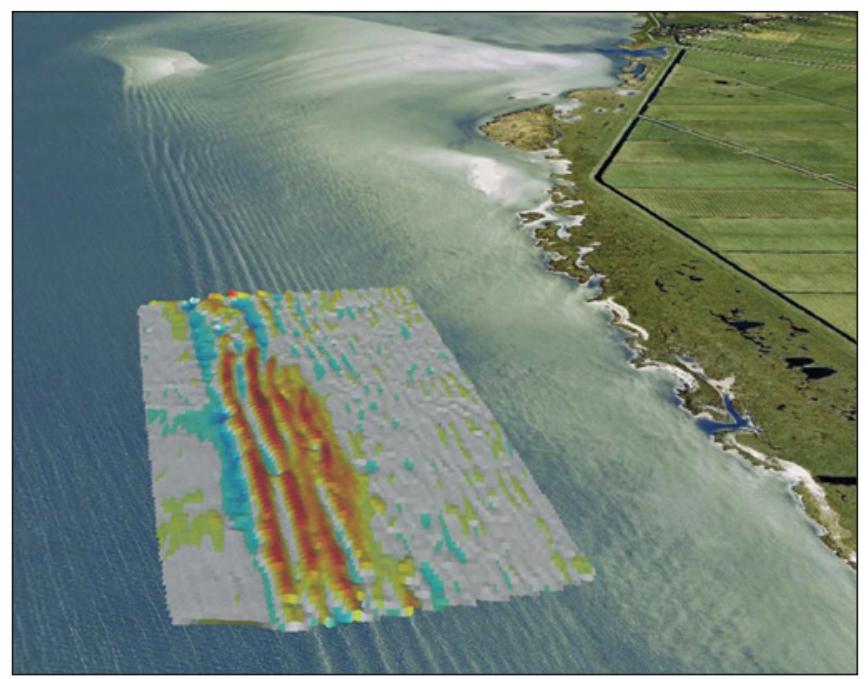

Figure 6. Workumerwaard shore nourishment scheme showing the bed topography after 1 year (warm colours higher, cold colours lower) the sediment is moving towards the shore but slower than expected 
Civil Engineering

Volume 167 Issue CE1 February 2014
'Building with nature': the new Dutch

approach to coastal and river works

de Vriend, van Koningsveld and Aarninkhof

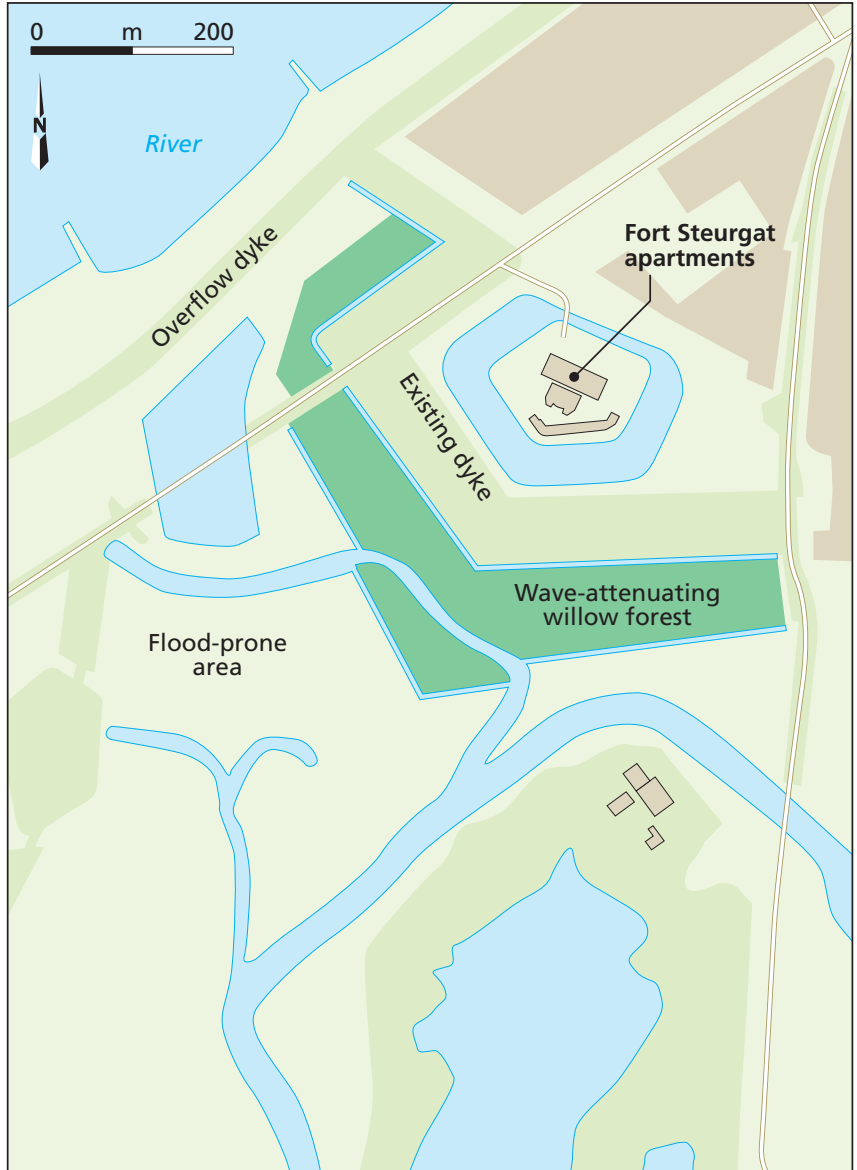

Figure 7. Plan of wave-attenuating willow forest scheme at Noordwaard - the trees allow the dyke to remain lower and less visually intrusive in the landscape
First monitoring results (Figure 6) show the formation of bed forms, which indicates that the area is morphologically active. So far, the shoreward movement of the nourishing sediment has been rather slow, although the process was accelerated by the action of ice piling up during a cold spell in February 2012. It is too early to judge whether the experiment can be considered a success.

\section{Flood defence}

Dykes are widely used in the Netherlands as a means to protect low-lying areas from flooding. These areas, however, are often sedimentation zones subject to compaction and subsidence and including thick layers of peat. Dykes in these areas therefore need raising from time to time, but cannot be made too heavy to avoid sinking into the soft subsoil.

Depending on the situation, wave run-up may determine the dyke height to a significant extent. So, if the incoming waves can be attenuated before they reach the dyke, the dyke can be kept lower and less heavy. Wave-attenuating shallow foreshores may have this function, while also providing a number of other services, such as dyke stabilisation and seepage-reduction (piping), nature reserve, recreation area and wood or biomass production. Wetlands like the Workumerwaard provide such services while reducing wave attack on the dykes behind them.

In the Netherlands, such solutions are being built, planned or considered at several locations.

Noordwaard, in the Biesbosch area of the Rhine-Meuse delta, where a wave-attenuating willow forest is placed in front of a dyke to keep the dyke low enough not to spoil the view of the people living behind it (Figure 7).

- Oesterdam, in the back of the Oosterschelde basin, which is provided with a shallow foreshore to reduce wave attack and increase the salt marsh area in the basin.

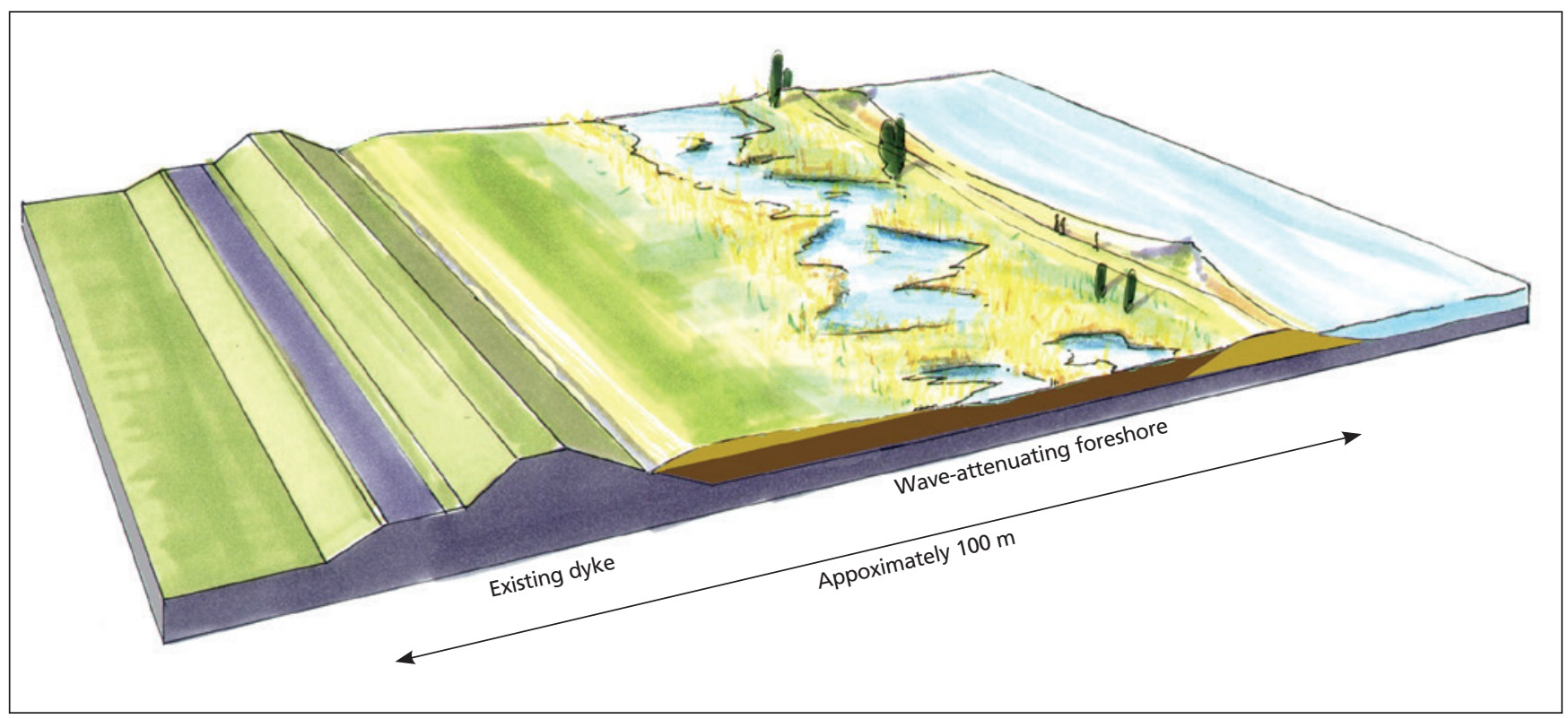

Figure 8. Artist's impression of a wave-attenuating shallow foreshore

for the Oeverdijk, Markermeer - the foreshore avoids raising the dyke,

which is built on a thick layer of peat 
- Sophia Beach, near the mouth of Oosterschelde, where a sandy dune and foreshore area will be created in order to avoid dyke strengthening.

- Oeverdijk, at the west side of the Markerwaard, a lake separated from the Ijsselmeer, where a wave-attenuating shallow vegetated foreshore is being considered to avoid raising a dyke built on a thick layer of peat (Figure 8).

- Hondsbossche sea defence, where a shallow sandy foreshore is planned to avoid raising the dyke by $7 \mathrm{~m}$.

- Prins Hendrik dyke at the Wadden Sea side of the isle of Texel, where a wave-attenuating and current-deflecting shallow foreshore is being considered to avoid dyke raising.

\section{Tropical shores}

Most of the cases considered above are located in the Netherlands, which is striving to become a test bed for the building with nature approach. However, the country cannot be a model for all other parts of the world, so the approach is also being tested in tropical areas. Issues there include reducing the environmental impact of hydraulic infrastructure; the use of ecosystem engineers such as coral, seagrass and mangrove for shore protection and erosion control; and improving the habitat suitability of hydraulic engineering structures.

Tropical ecosystems are generally rich and abundant and they provide many valuable services. As well as supporting diverse flora and fauna, they provide natural coastal protection by dissipating wave energy and by trapping and stabilising sediment. Marine infrastructure developments easily interfere with them, potentially having a significant environmental impact, but they are also essential for economic growth and coastal protection. Developing marine infrastructure while strengthening ecosystems is therefore a major challenge, especially in densely populated areas.

Applying a building with nature approach can help to minimise environmental impacts, starting from detailed analyses of the prevailing physical, ecological and social systems. In the case of tropical coastal waters, the analyses involve assessments of how coral reefs, seagrass meadows and mangroves respond to changes in turbidity and sedimentation. Once the effects of such changes are estimated, it is possible to adjust both the design of a project and its execution. In the case of dredging works, this means starting from the health of the ecosystem, rather than from the amount of overflow produced by the dredger. This opens the way to scientifically based and site-specific norms for dredging operations, instead of norms copied from elsewhere (Figure 9).

Another issue is how to encourage the development and use of ecosystems to provide multifunctional coastal protection. Coral reefs, seagrass meadows and mangroves, either alone or in combination, may offer natural and effective ways to prevent coastal erosion, as well as to enhance other ecosystem services such as water filtration and opportunities for fisheries and recreation.

Designing such ecosystem-based coastal protection is far from straightforward, because ecosystems need specific conditions to become established and survive. Seagrasses, for example, need soft substrates, adequate sunlight and relatively sheltered conditions, whereas coral larvae require hard substrates as well as sunlight. The challenge is to identify which of these conditions are missing and how they can be created in the design.

To demonstrate the applicability of the building with nature concept in tropical environments, an interdisciplinary design workshop with experts, stakeholders and local authorities was held to produce a pilot design of a multifunctional coastal protection scheme for the East Coast Park area of Singapore. Created on reclaimed land, with an artificial beach to meet the increasing demand for recreation space, this area of the coast is threatened by erosion and its ecological value is limited. The envisaged design solution should alleviate the coastal erosion, enhance the potential for recreation and strengthen biodiversity, while also taking into account the proximity of busy shipping lanes and housing developments (Figure 10).

\section{Translation into practice}

Building with nature solutions are tailor-made and cannot simply be copied to another location. This means that the concept, rather than the solutions, has to be communicated with the people considering future projects. In the framework of the Dutch building with nature innovation programme, this translation of site-specific knowledge and experience to general applicability is receiving a lot of attention. This has led to design guidelines, which are freely accessible on line (www.ecoshape.nl; see also de Vriend and van Koningsveld (2012)).

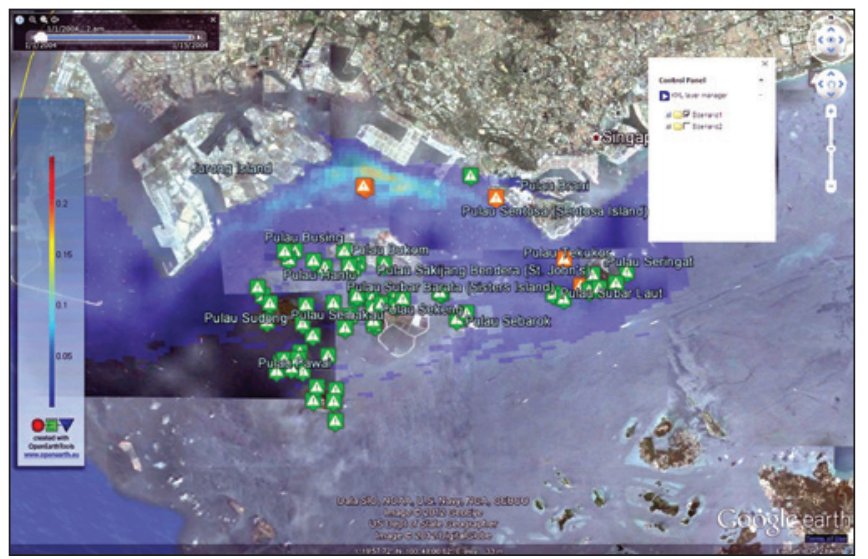

Figure 9. Screenshot of a test application in Singapore of an interactive impact-based support system for dredging operations, based on the response of a number of key species to turbidity and sedimentation green symbols indicate moderate impact, orange ones significant impact

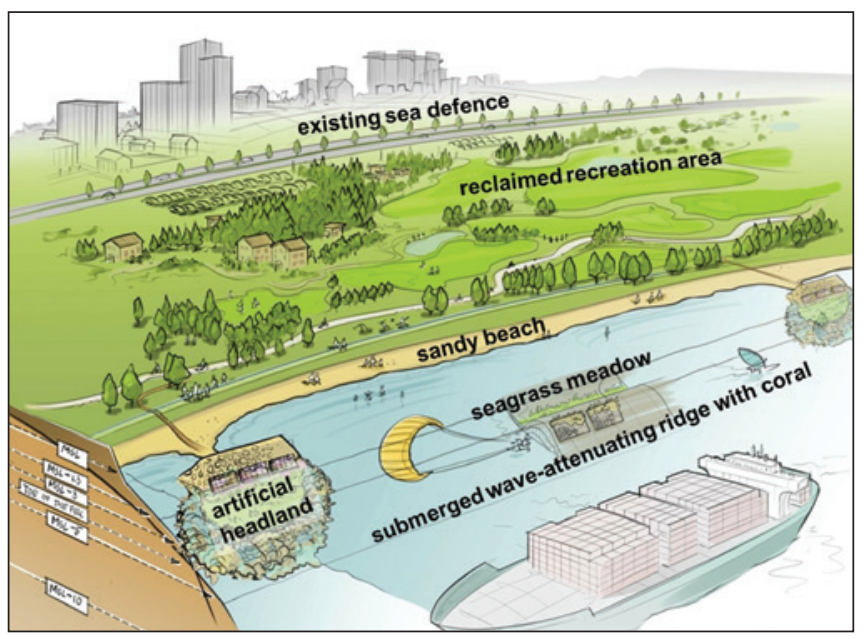

Figure 10. Result of a building with nature design workshop for East Coast Park, Singapore 
The guidelines challenge project developers, designers and users to think, act and interact differently. They start by introducing the building with nature philosophy, describe the various project phases (initiative, design, construction, operation and maintenance, dismantling) and then describe the main design principles and the five general design steps that are invariably involved in each phase: understanding the system, identifying solution alternatives, evaluating alternatives, fine-tuning the selected solution and preparing it for the next project phase. The large amount of material can be approached from different angles: by project phase, by type of environment and by governance level (Figure 11).

The guidelines are underpinned by the building with nature knowledge base, which consists of a wide range of enabling building blocks, a set of useful tools, a portfolio of example cases and knowledge pages on various topics addressed during the programme. On top of this, there are course materials and tutorials for individual learning and education programmes.

\section{Lessons learned}

Building with nature projects developed so far have provided a number of important lessons. The projects do not end by completion of the engineering works, since at that point nature, ecosystem services and sometimes also economic functions only start evolving. This means that post-project monitoring is crucial to operate and manage building with nature infrastructure.

Actors and stakeholders of infrastructure projects will not immediately embrace the building with nature concept as an alternative for or an add-on to traditional engineering. Therefore, it is important to introduce these ideas as early as possible into the development process, when crucial choices have not yet been made.

Since nature includes uncertainty, using nature as a component introduces an element of uncertainty into infrastructural works. The other side of this coin is adaptivity: the natural component may enable adaptation to changing environmental conditions. Building with nature implies consciously dealing with these aspects.

Building with nature is also building with society: building with nature projects usually affect the interests of many stakeholders and have a high visibility to the public at large. Involving stakeholders from the early stages of development and making them co-owner of the problem and its solution is therefore highly recommended.

Building with nature projects may involve extra construction costs over traditional engineering, yet be economically preferable when considering the entire project life cycle. Additional functions may yield extra benefits: nature's adaptive capacity may save future reconstruction costs

Environmental legislation such as the EU bird and habitat directives (EC, 1992, 2009) and Natura 2000 (http://ec.europa.eu/environment/ nature/natura2000/) rather stimulate than suppress a building with nature approach, thus enabling infrastructure development which would otherwise be impossible (Vikolainen, 2012).

\section{Acknowledgements}

Many of the cases presented in this paper are embedded in the Netherlands building with nature innovation programme, which is co-funded by the partners of the EcoShape consortium, the Rijkswaterstaat, the municipality of Dordrecht and the European Fund for Regional Development.

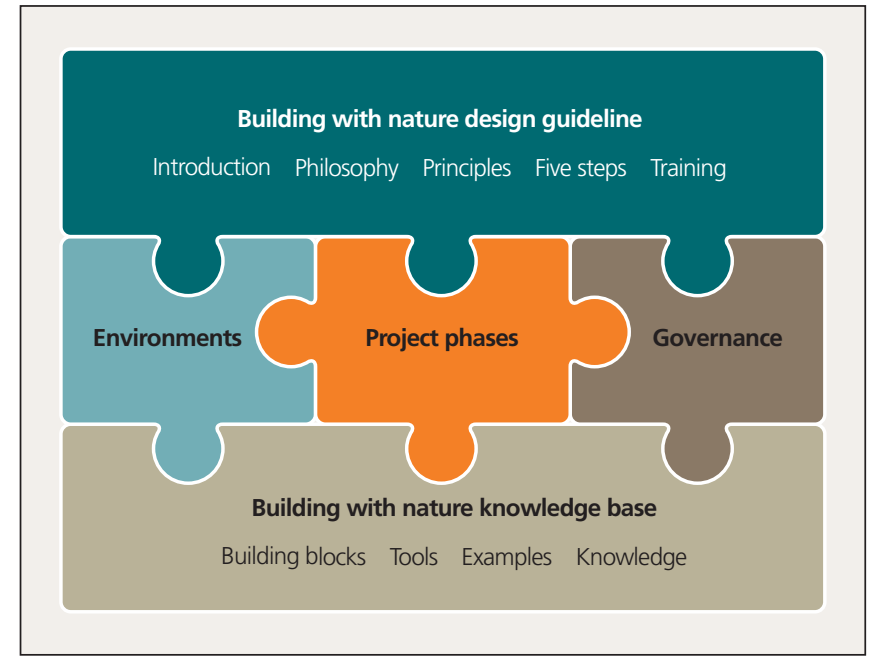

Figure 11. Structure of the building with nature guidelines - the approach can be varied to suit the type of environment, the project phase and the governance level

\section{References}

Baptist M, Tamis J, Borsje B and van der Werf J (2008) Review of the Geomorphological, Benthic Ecological and Biogeomorphological Effects of Nourishments on the Shoreface and Surf Zone of the Dutch Coast. Wageningen IMARES, Wageningen, the Netherlands, report Wageningen IMARES C113/8, Deltares Z4582.50.

de Vriend HJ and van Koningsveld M (2012) Building with Nature: Thinking, Acting and Interacting Differently. EcoShape, Building with Nature, Dordrecht, the Netherlands. See http://www.ecoshape.nl (accessed 08/10/2013).

EC (European Community) (1992) Council Directive 92/43/EEC of 21 May 1992 on the conservation of natural habitats and of wild fauna and flora. Official Journal of the European Communities L206/7.

EC (2009) Directive 2009/147/EC of the European Parliament and of the Council of 30 November 2009 on the conservation of wild birds. Official Journal of the European Communities L20/7.

McHarg I (1969) Design with Nature. Natural History Press, Garden City, NY, USA, re-published in Wiley series in sustainable design, 1995.

Stive M, Nicholls R and de Vriend H (1991) Sea level rise and shore nourishment: a discussion. Coastal Engineering 16(1): 147-163.

Stive MJF, Fresco LO, Kabat P, Parmet BWAH and Veerman CP (2011) How the Dutch plan to stay dry over the next century. Proceedings of the Institution of Civil Engineers - Civil Engineering 164(3): 114-121, http://dx.doi. org/10.1680/cien.2011.164.3.114

Vikolainen V (2012) Nature at Work: the Feasibility of Building with Nature Projects in the Context of EU Nature 2000 Implementation. PhD thesis, University of Twente, Enschede, the Netherlands.

Waterman R (2008) Integrated Coastal Policy via Building with Nature. RE Waterman, Delft, the Netherlands.

World Bank (2010) Word Development Report 2010: Development and Climate Change. World Bank, Washington, DC, USA.

\section{What do you think?}

If you would like to comment on this paper, please email up to 200 words to the editor at journals@ice.org.uk.

If you would like to write a paper of 2000 to 3500 words about your own experience in this or any related area of civil engineering, the editor will be happy to provide any help or advice you need. 